\title{
Symposium review: Linking activity-sensor data and physiology to improve dairy cow fertility*
}

\author{
R. L. A. Cerri, ${ }^{1} \dagger$ T. A. Burnett, ${ }^{1}$ A. M. L. Madureira, ${ }^{1}$ B. F. Silper, ${ }^{1} \ddagger$ J. Denis-Robichaud, ${ }^{2} \S$ S. LeBlanc, ${ }^{2}$ \\ R. F. Cooke, ${ }^{3}$ and J. L. M. Vasconcelos ${ }^{4}$ \\ ${ }^{1}$ Applied Animal Biology, Faculty of Land and Food Systems, University of British Columbia, Vancouver, BC, Canada, V6T 1 Z4 \\ ${ }^{2}$ Department of Population Medicine, University of Guelph, Guelph, ON, Canada, N1G 2W1 \\ ${ }^{3}$ Department of Animal Science, College of Agriculture and Life Sciences, Texas A\&M University, College Station 77843 \\ ${ }^{4}$ Department of Animal Production, Faculty of Veterinary Medicine and Animal Science, São Paulo State University, Botucatu, Brazil, $18160-000$
}

\section{ABSTRACT}

Several studies have demonstrated that the intensity of estrous expression is associated with ovulation, ovarian and uterine function, and fertility, and is dependent on social hierarchy and the housing system used. Data from recent studies involving spontaneous and induced estrus have shown that a greater relative increase and longer estrus (captured by different automated activity monitors; AAM) are both associated with improved pregnancy per artificial insemination (AI; around 10 to $14 \%$ increase) and decreased pregnancy losses. Intensity and duration of estrus were surprisingly weakly associated with preovulatory follicle diameter and concentrations of plasma estradiol at estrus, whereas ovulation failure was associated with low estrus intensity. Studies have also shown that the display of estrous behavior near AI was associated with the modification of expression of genes related to the immune system, adhesion molecules, and prostaglandin synthesis in the endometrium. Transcripts in leukocytes and in the conceptus tissue associated with maternal recognition of pregnancy as well as conceptus elongation were all associated with differences in the intensity of estrous expression. Most recently, studies from the United States and Canada have demonstrated that reproductive programs emphasizing detection of estrus using AAM can be successful and comparable to intensive timed AI protocol-based programs that incorporate GnRH and $\mathrm{PGF}_{2 \alpha}$ treatments. Further, one study concluded that the administration of GnRH at AI for spontaneous estrus events greatly improved pregnancy per

Received November 11, 2019.

Accepted July 15, 2020.

*Presented as part of the CSAS Symposium: From Data to Decisions-The Next Step for Technology in Dairy Production at the ADSA Annual Meeting, Cincinnati, Ohio, June 2019.

†Corresponding author: ronaldo.cerri@ubc.ca

†Currently at Zoetis Inc., São Paulo, SP, Brazil.

$\S$ Currently at Vector Consulting, Amqui, QC, Canada.
AI, but only for cows with reduced intensity of estrous expression, showing the potential to use AAM data as a tool in targeted reproductive programs. Quantitative information from estrus events could be used to improve estrus detection and develop decision-making strategies at the farm level. Future studies in this field should aim to better understand ovarian, conceptus, and endometrial mechanisms associated with either the expression or the intensity of estrus, and to refine the identification of phenotypes related to estrus (relative increase, absolute increase, baseline levels, duration, and repeatability within cow) to improve data usage, estrus detection, and possibly genetic selection.

Key words: activity monitors, estrus, dairy cow, precision dairy technologies

\section{INTRODUCTION}

Recent studies have shown that the display of estrous behavior and the intensity of these behaviors seem to have a substantial effect on fertility of dairy cattle (Madureira et al., 2015, 2019b; Burnett et al., 2017, 2018; Silper et al., 2017). Previous studies that modified different aspects of the estrous cycle, such as the length of follicular dominance (Cerri et al., 2009), concentrations of progesterone during diestrus (Cerri et al., 2011; Bisinotto et al., 2015), and proestrus length and estradiol exposure (Bridges et al., 2008), have described effects on ovarian dynamics, fertilization, embryo quality, and uterine environment. Similarly, other authors have also described mechanistic explanations involving production and health effects (Sartori et al., 2002; Ribeiro et al., 2016) on reproductive tissues and overall fertility. However, in spite of marked effects related to the aforementioned modifications of the estrous cycle, little emphasis was previously placed on the sole or additive effects or associations of expression of estrus on reproductive tissues. The association of the occurrence of estrus and the intensity of estrous expression on fertility will be discussed in this paper, but it is clear 
that estrus has an important positive effect on fertility, which leads to questions regarding the physiological mechanisms associated with these improvements.

Because of the extensive use of automated activity monitors (AAM) in parts of North America and Europe, large amounts of information regarding the detection and behavioral profile of the time of estrus have become available to correlate with actual physiological events. This paper will therefore follow a rationale that includes the effects or association of estrus on (1) production parameters and expression of estrus, (2) AAM, estrus, and fertility, (3) mechanistic factors linking estrous expression and fertility, and (4) reproductive programs.

\section{PRODUCTION PARAMETERS AND EXPRESSION OF ESTRUS}

The detection of estrus in confined dairy cows has become a greater challenge as milk production has increased. Previous studies that account for only mounting behaviors as a measure of intensity and duration of estrus have consistently recorded a decrease in these behaviors in cows with greater milk production (Lopez et al., 2004; Rivera et al., 2010). In a recent survey, Denis-Robichaud et al. (2016) reported that the estrus detection rate according to visual assessment of mounting behavior was less than $50 \%$, although the proportion of cows truly bred upon estrus detection was unclear, as their data are confounded by the use of timed AI. Because confined dairy cattle are housed in an environment less conducive to mounting behaviors (e.g., slippery flooring; Stevenson, 2001), it raises the concern that mounting behavior may no longer be ideal as a gold standard for estrus detection.

A large field study (López-Gatius et al., 2005) found that the 2 main factors associated with the magnitude of activity increase at estrus were lactation number and milk production, and noted that the degree of increase in activity was positively correlated with fertility after AI. However, until recently, few studies reported more detailed physiological measurements associated with spontaneous estrous behaviors and intensity of activity measured using AAM systems. Moreover, robust studies have now become available with adequate statistical power, allowing for more reliable conclusions.

\section{Parity, Milk Production, and BCS}

A study by our group identified several risk factors associated with intensity of estrous expression (Madureira et al., 2015). In this study, multiparous cows expressed a lower intensity of estrous expression and had estrus episodes with shorter duration compared with primiparous cows. Similarly, López-Gatius et al. (2005) reported that walking activity at estrus was reduced by $21.4 \%$ for every increase in lactation number. In contrast, other studies have reported primiparous cows to have shorter (Walker et al., 1996) or no difference (Veerkamp et al., 2000; Løvendahl and Chagunda, 2010) in physical activity at estrus compared with multiparous cows. Methodological differences may explain variation among different studies on the association between parity and physical activity, such as how the recording interval or block of data are defined, and different breeds of cows.

Greater milk production has been negatively correlated with standing to be mounted at estrus (Lopez et al., 2004; Rivera et al., 2010). Holman et al. (2011) found that milk production does affect the overall sensitivity of pedometers or activity monitors to detect true events of estrous behaviors. The decrease in concentrations of estradiol, possibly caused by increased hepatic blood flow and steroid clearance (Vasconcelos et al., 2003), is a possible cause for decreased estrusrelated behavior due to milk production. Madureira et al. (2015) also found greater intensity and duration of estrous expression in cows with lower milk production, but the difference was only for the lowest quartile $(\leq 31.3 \mathrm{~kg} / \mathrm{d})$. We could assume that the data partially agree with previous research (Lopez et al., 2004; Rivera et al., 2010); however, it seems that mounting activity is more affected than overall physical activity measured by AAM systems, as multiple studies by our group have not found a strong association of milk production with estrous expression measured by AAM (Burnett et al., 2017, 2018). Other studies from our group (Silper et al., 2015c) found that heifers and cows with lower baseline levels of activity tend to have greater relative activity increase, but not necessarily greater absolute increases in step counts during estrus. In spite of such results, intensity of physical activity during estrus was only weakly associated with milk production when illustrated on a scatter plot (Figure 1), indicating that other influences may be more important, such as BCS and parity, and likely factors such as group size, health status, and lameness (López-Gatius et al., 2005; Morris et al., 2009). It is difficult to establish this relationship because cows with lower milk production might be sick from diseases that also affect the reproductive tract, whereas high-producing cows are often in better overall health (Santos et al., 2009). This highlights the importance of study design and analyses to address the influence of confounders on these associations.

Body condition score was the major factor associated with estrous expression using AAM and its association with pregnancy per AI (Madureira et al., 2015). These findings support Løvendahl and Chagunda (2010), who 


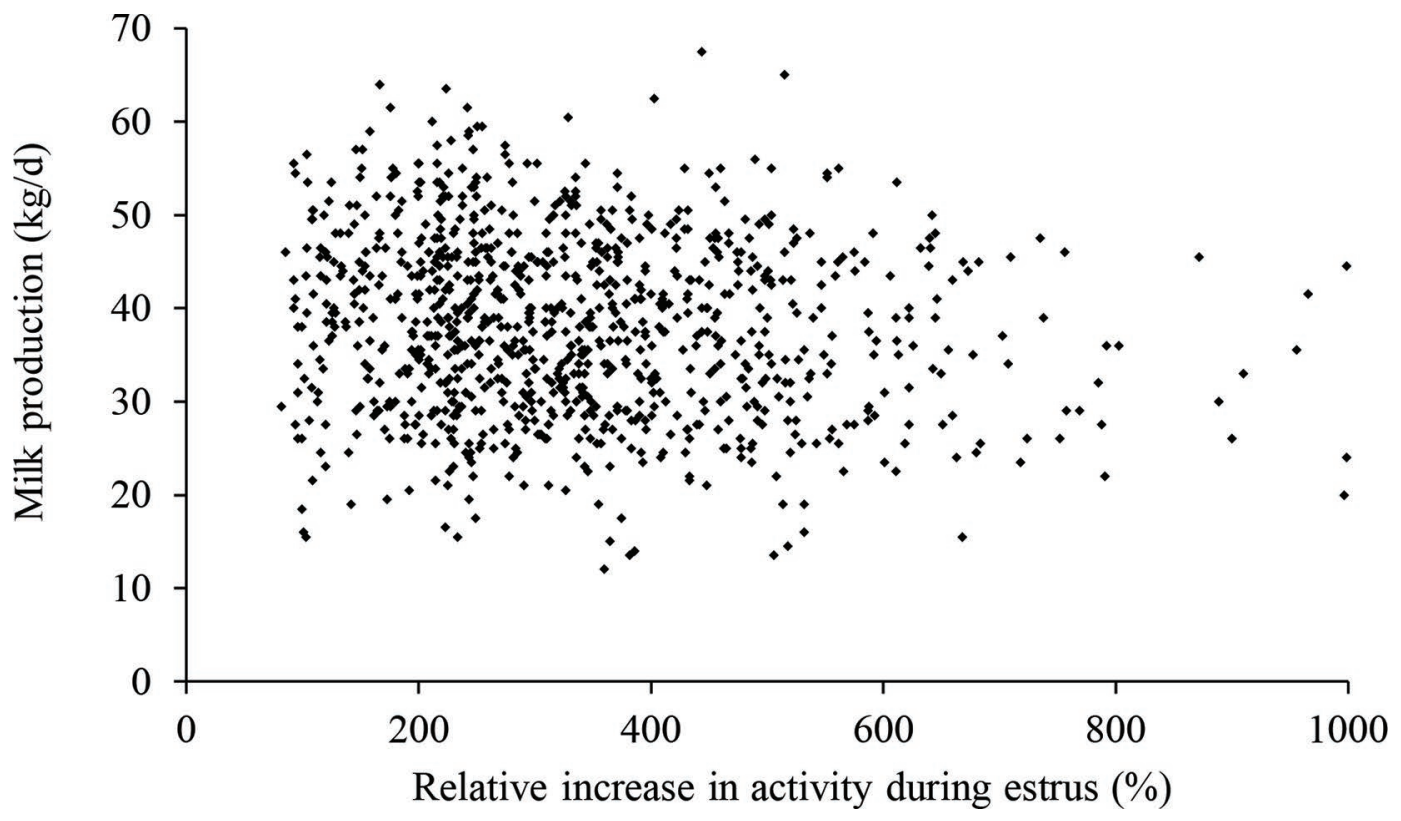

Figure 1. Scatter plot of milk production $(\mathrm{kg} / \mathrm{d})$ on the day of AI and percent relative increase in activity during estrus detected by a legmounted automated activity monitor (Boumatic Heat-seeker-TX, Boumatic Dairy Equipment Co., Madison, WI) in 1,041 estrus events from 346 milking cows in Canada (Madureira et al., 2015). The Pearson correlation coefficient (r; corr procedure, SAS, SAS Institute Inc., Cary, NC) between the 2 variables was $0.05(P<0.01)$.

observed reduced estrous expression in cows that had low BCS in the first 5 mo after calving. Aungier et al. (2012) also found an association between BCS and estrous expression, where a 0.25 increase in BCS was associated with increased physical activity before ovulation. The reduction in estrogen-dependent estrous behavior, caused by a temporary state of negative energy balance, has also been noted in beef cows (Rodrigues et al., 2018).

\section{AUTOMATED ACTIVITY MONITORS, ESTRUS, AND FERTILITY}

Several AAM systems are available for dairy farmers, but further development of this technology is still necessary. Some of these systems have resources such as adaptable thresholds per farm or groups of cows, but these do not seem to be explored, described, or extensively used. For example, adjustments to algorithms could be made according to season of the year, parity, and BCS; however, these adjustments only illustrate the challenge ahead of the dairy industry regarding the rapid transition toward heavy use of data and automation. Moreover, detailed information about different AAM systems will be key to properly associate automated behavior data with physiological parameters. In a simple analysis by our group comparing a neck- mounted and a leg-mounted AAM, the correlation between the intensity of estrus episodes of
2 different systems was acceptable but perhaps not at a level that justifies a seamless translation of the data from one system to the other (Sakaguchi et al., 2007; Madureira et al., 2015; Silper et al., 2015a). Different AAM systems will capture different movements, and different algorithms and software filter the background data in a specific manner, influencing measurements of baseline levels and relative increases in activity during estrus.

\section{Use of AAM in North America}

A few studies, most often large surveys, have been able to draw a picture of the state of reproductive programs in North America. Caraviello et al. (2006) found that over half of all dairy farms in the United States used timed AI programs, but at the time (mid-2000s) no figures were available on the use of AAM on American and Canadian farms, likely indicating its low adoption by farmers. In Canada, a recent large survey indicated mixed use of reproduction programs based on visual detection, timed AI, and AAM, which were highly affected by the location of the farm. For example, the region of Quebec, which concentrates a large number of tiestall farms with a small herd size (approximately 50 cows), used fewer AAM systems than did British Columbia, where well over half of herds detect estrus based on AAM systems (Denis-Robichaud et al., 2016). In this survey, results from 772 farms were reported, 
representing $6 \%$ of all dairy farms in Canada (DenisRobichaud et al., 2016). Automated activity monitor systems were used in $28 \%$ of the participating herds (4\% of tiestall but $59 \%$ of freestall herds), and activity alerts were checked at least twice daily by almost all $(92 \%)$ users. Interestingly, $21 \%$ of users never confirmed heat by visual observation before insemination, and $26 \%$ always did. Results from this survey highlight the variability in reproduction management among Canadian dairy herds. In a sister survey from the same research group (Denis-Robichaud et al., 2018a), the authors found that improving performance was the main factor influencing decisions concerning reproduction for $80 \%$ of respondent farmers, and farmers adopted tools and technologies such as synchronization programs and AAM systems to improve herd reproductive performance. However, more research is likely required to describe how this performance is defined and perceived by respondents and how it relates to actual variability of performance (i.e., pregnancy rate) among farms.

\section{Automated Activity Monitors}

Automated activity systems can be different regarding their output or variable to be analyzed (e.g., step counts, acceleration of movement, rumination time or frequency, lying time or bouts). The comparison between systems is challenging, as their accuracy (sensitivity, positive predictive value, and daily error rate) is not always calculated using the same reference for evaluation (e.g., progesterone profile). Although the most appropriate way to calculate these parameters could be debated, previous research generally concluded that commercial AAM systems were efficient at detecting estrus. For example, using a neck-mounted device (Heatime; SCR Engineers, Netanya, Israel), Valenza et al. (2012) detected $71 \%$ of the preovulatory phases but missed $13 \%$ of the recorded ovulations. Using the same sensors, Aungier et al. (2012) reported $72 \%$ of the preovulatory follicular phases identified correctly but $32 \%$ false positives, whereas LeRoy et al. (2018) found that an AAM detected $83 \%$ of cows in estrus by 80 DIM. In the studies conducted by our group (Madureira et al., 2015; Silper et al., 2015c), the positive predictive value for estrus alerts has been approximately $85 \%$. A study from Denmark using activity tags (Alpro; DeLaval, Tumba, Sweden) showed a $74.6 \%$ detection rate and $1.3 \%$ daily error rate when using the most efficient algorithm calculated by the authors (Løvendahl and Chagunda, 2010), whereas an early study from the Netherlands (Roelofs et al., 2005) found that between 51 and $87 \%$ for all estrous periods were detected by pedometer measurements.
Little research has been performed on the use of lying and standing behavior for estrus detection. Rutten et al. (2013) reviewed 48 papers, but only 2 reported lying and standing information (Brehme et al., 2008; De Mol et al., 2009). Our research group has analyzed lying and standing information in relation to the estrous period in greater detail (Silper et al., 2015b, 2017). Results from these studies indicate a large potential for improving the accuracy of estrus detection, as well as the use of quantitative information (e.g., proportional changes in lying behaviors on the day of estrus in relation to the day before and after) from these monitors to assist farm-level decision-making regarding breeding. To our knowledge, only one paper from 10 years ago (Brehme et al., 2008) described the absence of lying over long periods $(16 \mathrm{~h})$ during estrus. However, that paper did not provide detailed information about measurements or factors that affect lying time. Given the variability reported by many and the low levels of estrous expression in general, it seems that combining measurements within one system is potentially a better alternative for reducing false negatives. A combination of activity and lying behavior data from a specific AAM system significantly reduced error rate (false alerts) and increased the probability of estrus detection (Jónsson et al., 2011). Peralta et al. (2005) also suggest that combinations of systems are the best alternative to enhance detection and conception rates during periods of heat stress. The use of more than one measurement within the same sensor can also enhance specificity and reduce false positives (Firk et al., 2002).

\section{Effect of Detection and Intensity of Estrus on Pregnancy per Al and Pregnancy Loss}

In a series of recent studies using different AAM systems and multiple farms, substantial increases in pregnancy per AI were observed when estrus events had greater intensity of physical activity (Madureira et al., 2015, 2019b; Burnett et al., 2018) and large decreases in lying time (Silper et al., 2017). Consistently, cows with greater intensity of estrous expression had greater rates of pregnancy per AI (10 to 14 percentage units) than did cows with reduced intensity (Madureira et al., 2015, 2019b; Burnett et al., 2018). This association is illustrated in Figure 2 (Madureira et al., 2015), which shows that cows expressing a relative increase in activity $\geq 300 \%$ (greater intensity) had a 14 percentage unit greater rate of pregnancy per AI than cows expressing estrus of low intensity. Previously, López-Gatius et al. (2005) reported an improvement in fertility associated with relative increase in walking activity. It is possible that information already available in herd management 


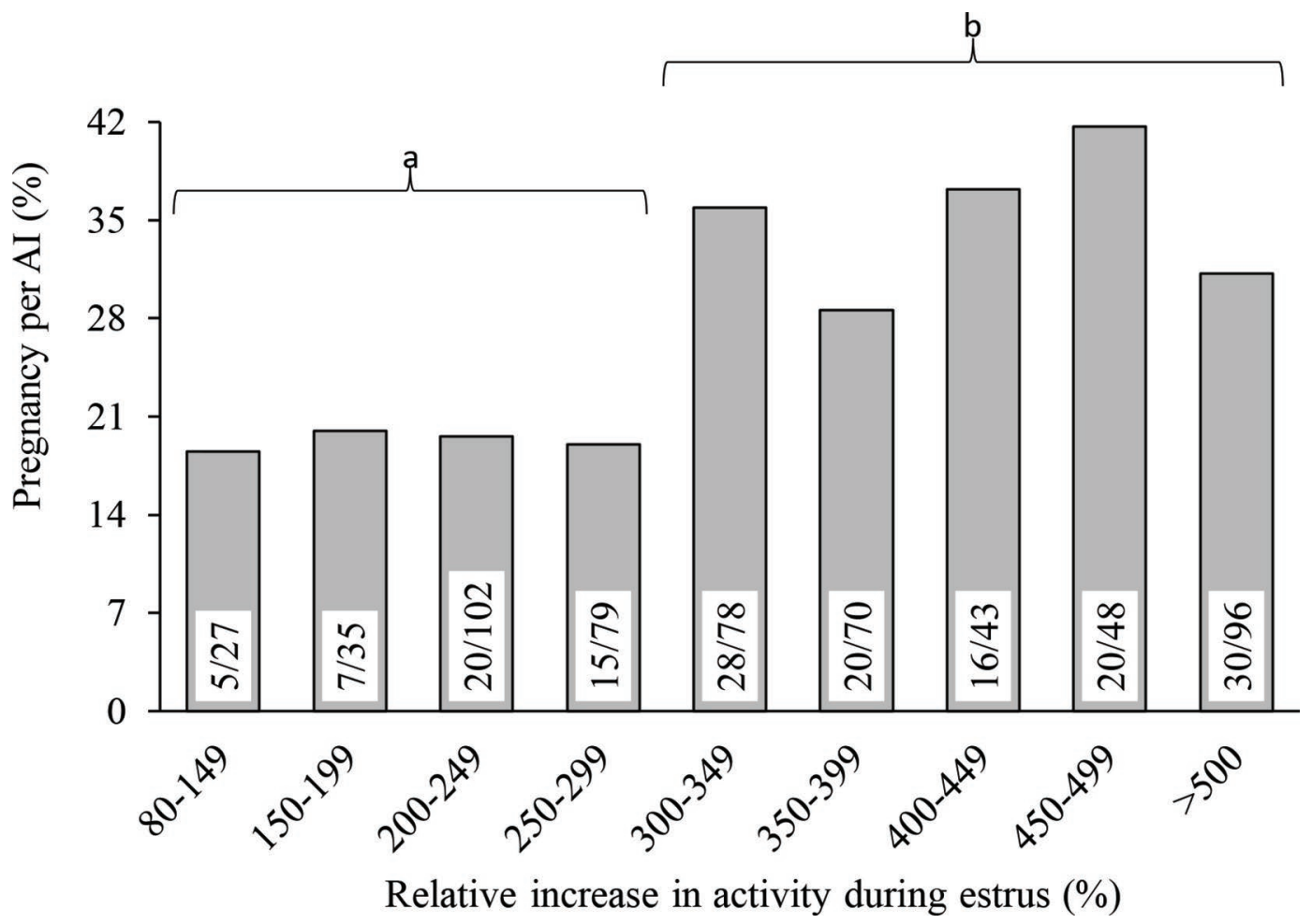

Figure 2. Distribution of pregnancy per AI (\%) according to percent relative increase in activity during estrus detected by an automated activity monitor (Boumatic Heat-seeker-TX, Boumatic Dairy Equipment Co., Madison, WI). Statistical analysis for the pregnancy per AI used logistic regression adjusted for parity and BCS in 1,041 estrus events from 346 milking cows in Canada (Madureira et al., 2015). Inseminations following estrus with a relative increase in activity $<300 \%$ were less likely to result in a pregnancy than estrus with a relative increase in activity $\geq 300 \%$. Lowercase letters (a, b) denote significant differences $(P<0.05)$.

software could be used to calibrate AAM to take into account BCS, parity, milk production, and health parameters of the cow, as well as the typical herd conditions such as pasture systems, milking frequency, and stocking density.

The thresholds used by our group to distinguish the categories of greater or lower intensity of estrus were initially found via retrospective analysis (Madureira et al., 2015; Silper et al., 2015c, 2017). In those initial studies, no literature categorized the intensity of estrus captured by AAM systems based on pregnancy per AI or other physiological parameters, such as ovulation rates and timing, uterine environment, and ovarian dynamics. In addition, as previously noted, different systems display estrus alerts showing intensity scales that do not directly reflect activity behavior itself but, rather, a transformed number or index created by the manufacturer's algorithm. Even with these limitations, it is possible to specify an approximate threshold to categorize estrus intensity in lactating cows in freestall barns. In general, the threshold falls close to the median intensity of the herd, which translates into a relative (to baseline) increase in activity of about 300\% (Madureira et al., 2015, 2019b). For example, in practical terms, this threshold is close to the 80 Index of the SCR system (Heatime HR), or in the 250 to 300 Heat Indicator range of the AfiMilk system (AfiActII; AfiMilk, Afikim, Israel).

The occurrence of estrus at timed AI, but without the distinction of intensity, has been associated with a reduction in pregnancy losses (Pereira et al., 2014). These results were confirmed in a subsequent large field study from the same group in Brazil (Pereira et al., 2016). Moreover, the latter study showed that this effect is true for both AI and embryo transfer (ET)-based programs, indicating a possible major modification of the uterine environment as the cause for improved fertility. Most recently, another data set from Brazil (Madureira et al., 2019b) also demonstrated the significant effect of estrus intensity on pregnancy loss. Cows with greater intensity of estrus had decreased late embryonic or early fetal losses (Figure 3), suggesting that conceptus-endometrium communication is compromised in multiple stages of early gestation. This practical result from Pereira et al. (2016) and Madureira et al. (2019b) corroborates data from nonlactating beef cows that showed extensive 
modulation of endometrial gene expression (Davoodi et al., 2016; Souto et al., 2018). Collectively, the results of these recent studies suggest that estrous expression is associated with important positive effects on gestation maintenance, particularly on the endometrium environment that is more suitable for conceptus development.

\section{MECHANISTIC FACTORS LINKING ESTROUS EXPRESSION AND FERTILITY}

\section{Ovarian Follicles and Estradiol}

The correlation between the preovulatory follicle diameter and plasma estradiol tends to be weak in heifers (Silper et al., 2015a; r $=0.17$ ) and is in agreement with values reported in multiparous cows (Sartori et al., 2004; Walker et al., 2008). Although other reports have found that a larger follicle is associated with greater concentration of estradiol in plasma (Cerri et al., 2004; Galvão et al., 2004), recent experiments showed that parity, BCS, and ultimately milk production are the factors with the greatest influence on circulating concentrations of estradiol. Cows classified as having greater intensity of activity at estrus had preovulatory follicle diameter not significantly different but slightly greater concentrations of estradiol in plasma than cows classified with reduced intensity of activity (Madureira et al., 2015). In spite of the differences in estradiol concentrations found when cows were divided in categories by estrus intensity, the total intensity measured by different AAM systems was weakly correlated with concentration of estradiol in plasma, demonstrating greater-than-expected variation. A study by Aungier et al. (2015) also observed no correlation between activity clusters measured by AAM with FSH, LH, and estradiol concentrations. Nonetheless, a greater peak concentration of estradiol in plasma was associated with standing and estrus-related behaviors.

\section{Ovulation Failure and Timing}

Ovulation failure and timing have been shown to differ with estrous expression. Lesser intensity (Burnett et al., 2018) and shorter duration (Hockey et al., 2010; Valenza et al., 2012; Stevenson et al., 2014) of estrous expression have been associated with shorter intervals from AAM estrus alerts to ovulation (Figure 4). In addition to the time of ovulation, less estrous expression has also been associated with increased ovulation failure both at spontaneous estrus events (1.9 vs. 9.5\%; Burnett et al., 2018) and at timed AI (5.1 vs. 11.8\%; Silper et al., 2017; Madureira et al., 2019b). Research investigating the occurrence of estrus at the end of timed

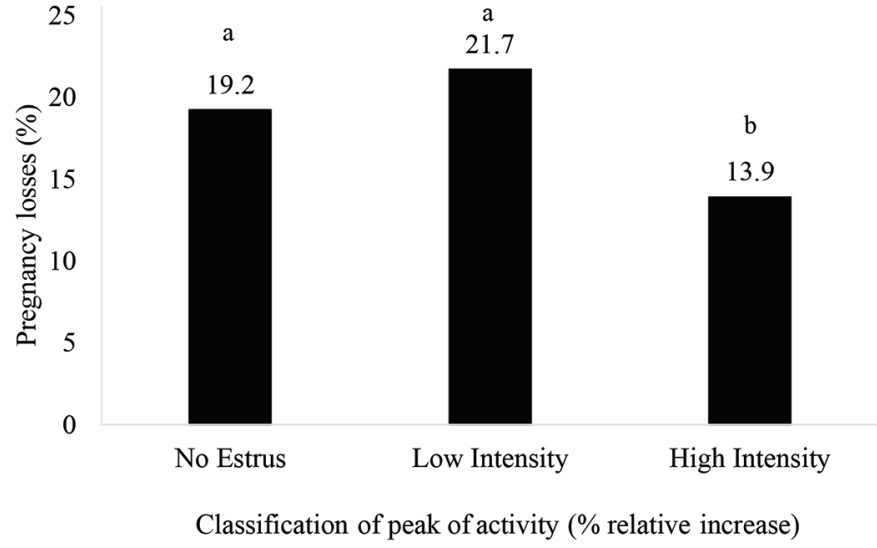

Figure 3. Distribution of pregnancy loss (\%) between d 32 and 60 of gestation according to categories based on percent relative increase in activity during estrus detected by an automated activity monitor (AfiPedometer Plus Tag; AfiMilk, Afikim, Israel) after cows were subjected to a timed AI protocol [d -11: 2-mg estradiol benzoate injection and insertion of a progesterone releasing device (CIDR); $\mathrm{d}-4$ : 12.5-mg $\mathrm{PGF}_{2 \alpha}$ injection; $\mathrm{d}-2$ : removal of CIDR, and 0.6-mg estradiol cypionate]. Statistical analysis for pregnancy loss used logistic regression adjusted for parity and BCS. Cows were categorized as no estrus $(<100 \%$ relative increase), low intensity (100-299\% relative increase), or high intensity ( $\geq 300 \%$ relative increase) in 1,411 estrus events from 1,040 milking cows in Brazil (Madureira et al., 2019b). Lowercase letters $(\mathrm{a}, \mathrm{b})$ denote significant differences $(P<0.05)$.

AI protocols using tail chalk also reported increased ovulation success in cows displaying estrous behavior than in those not displaying such behavior (Galvão et al., 2004; Pereira et al., 2014). In general, of all estrus episodes detected by different AAM systems, about 5 to $7 \%$ fail to ovulate. However, most of that failure has been associated with cows expressing reduced intensity of estrous, as previously discussed. It is important to note that some of the mentioned studies used estradiol cypionate (currently banned in the European Union and no longer available in the United States) to induce estrus and ovulation (Silper et al., 2017; Madureira et al., 2019b), which would greatly increase circulating estradiol concentrations. In spite of this difference, the estrus intensity measured by an AAM system was still significantly associated with ovulation timing, failure, and pregnancy per AI results.

\section{Progesterone}

In a study conducted by Bisinotto et al. (2015), the authors aimed to modify concentrations of progesterone during growth of the preovulatory follicle, comparing the first follicular wave with the second. Animals that ovulated follicles from the first follicular wave, growing under low concentrations of progesterone in plasma (worst possible scenario in that study), but that 


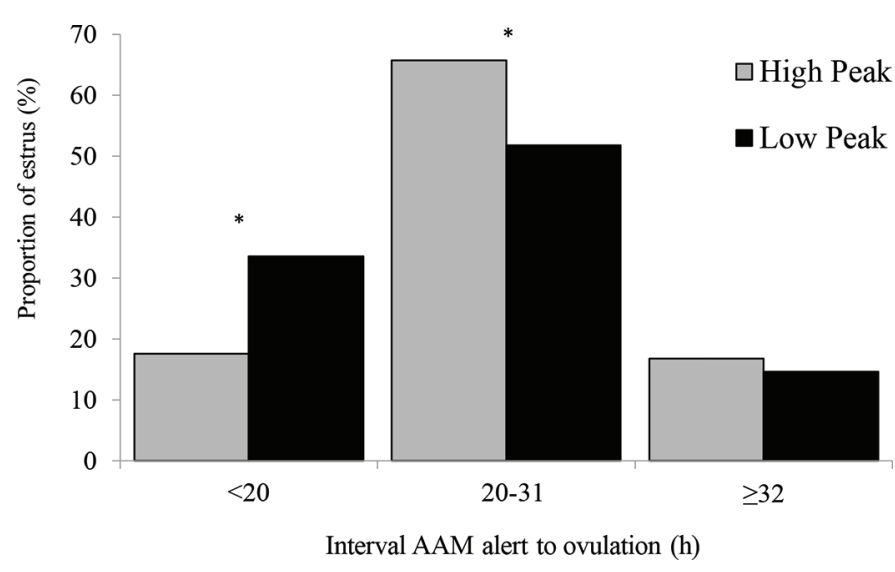

Figure 4. Frequency of estrus events with high (index $\geq 80$ ) and low (index $<80$ ) peak of activity, as measured by automated activity monitor (AAM; Heatime, H-Tags, SCR Engineers, Netanya, Israel) for 3 categories of intervals between AAM alert and ovulation $(<20 \mathrm{~h}$, 20-31 h, and $\geq 32 \mathrm{~h}$ ), in 850 estrus from 293 milking cows in Canada (Burnett et al., 2018). Peak activity was defined as the maximum activity during an episode of estrus. ${ }^{*}$ Denotes significant differences between estrus with high versus low peak of activity $(P<0.01)$.

expressed estrus at AI, had pregnancy per AI similar to rates of the treatments with optimal concentrations of progesterone; hence, the expression of estrus was directly associated with somehow improving embryonic survival. One possible mechanism is that increased concentrations of progesterone during the diestrus phase is associated with cows expressing estrus events of greater intensity (Denis-Robichaud et al., 2018c; Madureira et al., 2019a). A study just completed by our group (Madureira et al., 2018) aimed to determine the association between estrous expression, detected by AAM, and progesterone concentrations at AI (665 events) and following AI (171 estrus events). Cows displaying greater estrus intensity had lesser concentrations of progesterone at estrus $(1.0 \pm 0.2 \mathrm{ng} / \mathrm{mL}$ vs. $0.3 \pm 0.2$ $\mathrm{ng} / \mathrm{mL}$ ) and significantly greater progesterone on $\mathrm{d} 7$, 14 , and 21 after estrus $(3.4 \pm 0.2$ vs. $2.7 \pm 0.2 \mathrm{ng} / \mathrm{mL}$; $4.9 \pm 0.4$ vs. $2.9 \pm 0.4 \mathrm{ng} / \mathrm{mL} ; 6.8 \pm 0.3$ vs. $5.4 \pm 0.3$ $\mathrm{ng} / \mathrm{mL}$, respectively). Similarly, Williams et al. (2018) also reported that approximately $30 \%$ of potential estrus events (low progesterone value between 2 high values) remained unrecognized by 2 activity methods, and progesterone values in these animals were higher on the potential day of estrus. It seems that cows that displayed more intense estrous expression had a more ideal progesterone profile during the estrous cycle. These results were corroborated by a subsequent study that evaluated the association between estrous expression and the duration of the previous and succeeding follicular and luteal phases (Madureira et al., 2019a). Overall, our group has partly concluded that the pro- gesterone profile of consecutive estrous cycles has an important and significant effect in the overall length of the luteal and follicular phases, as well as affecting intensity of estrous expression.

\section{Endometrium Transcriptome and Conceptus Development}

Relatively little emphasis has been placed on the isolated or additive association of expression of estrus on reproductive tissues, particularly the endometrium and conceptus before implantation. To date, some questions about the association of estrous expression and the transcriptome in the endometrium and conceptus development during the preimplantation period have been answered (Davoodi et al., 2016; Souto et al., 2018; Cooke et al., 2019). The study by Davoodi et al. (2016) collected endometrium samples and conceptuses on d 19 of gestation and found evidence that estrous expression is positively associated with the expression of target genes important for embryo survivability. Cows that expressed estrous behavior near AI had an improved profile of endometrium gene expression critical for suppressing the local maternal immune system and likely improving adhesion between endometrium epithelial cells and conceptus, as well as partly inhibiting the mRNA machinery for prostaglandin synthesis (Souto et al., 2018; Figures 5 and 6). Moreover, cows that displayed estrus yielded longer conceptuses $(38.3 \pm 2.8$ vs. $28.2 \pm 2.9 \mathrm{~cm}$ ), which can be associated with better chances of survival. In a different study by the same group, evaluating samples collected on d 15 of gestation (Cooke et al., 2019), estrous expression near the time of AI enhanced pregnancy establishment factors such as upregulation of $M X 2$ mRNA expression in blood and expression of IFNT mRNA in the conceptus, as well as increased conceptus elongation $(2.7 \pm 0.6$ vs. $1.0 \pm$ $0.6 \mathrm{~cm}$ ). Alternatively, expression of estrus may simply indicate an optimal function of many reproductive tissues related to the survivability of the early embryo.

\section{REPRODUCTION PROGRAMS}

Recent field trials have compared different degrees of combination of timed AI and AI upon estrus detection using AAM. Conception risk (30\% vs. 31\%) and days to pregnancy (137 and $122 \mathrm{~d}$ to pregnancy) were not different among cows bred by timed AI or following estrus detection by an AAM system (Neves et al., 2012). Other studies have experimented with different combinations of use between AAM and timed AI programs (Valenza et al., 2012; Fricke et al., 2014; Stevenson et al., 2014; Burnett et al., 2017; Denis-Robichaud et al., 2018b). 


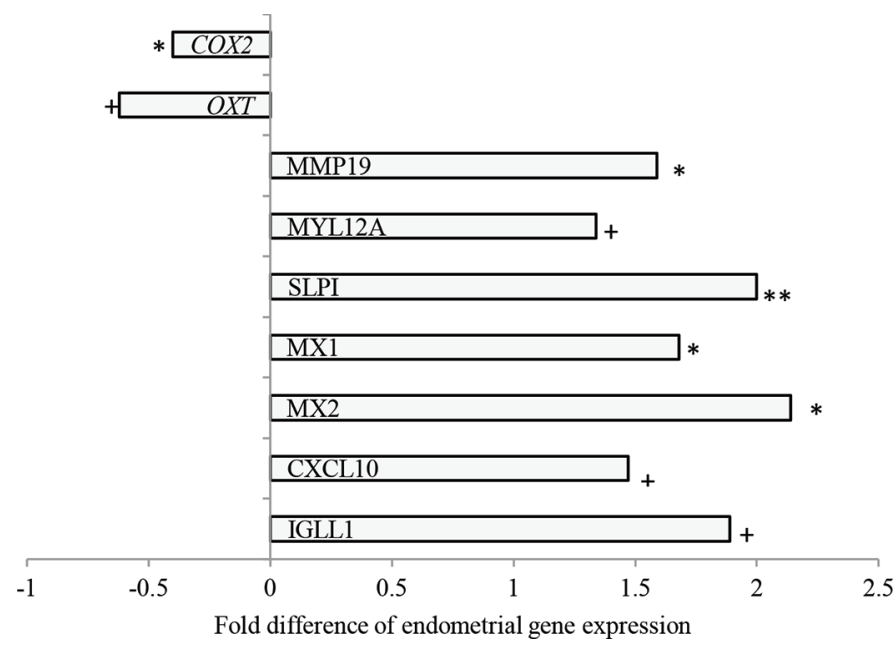

Figure 5. Fold difference obtained from linear regression models of the expression of each endometrium gene at d 19 of gestation in cows that expressed estrus signs (mounting and secondary signs) at insemination (referent: no estrus sign), adjusted for confounders (BCS, corpus luteum size, progesterone concentration, embryo length), in 36 nonlactating multiparous beef cows in Brazil (Davoodi et al., 2016). All inseminations were performed at fixed time, following an estrus synchronization protocol [d -11: 2-mg estradiol benzoate injection and insertion of a progesterone releasing device (CIDR); $\mathrm{d}-4$ 12.5-mg $\mathrm{PGF}_{2 \alpha}$ injection; $\mathrm{d}-2$ : removal of CIDR, and 0.6-mg estradiol cypionate and 300-IU equine chorionic gonadotropin injections; d 0: insemination). Only genes for which the regression model had a $P$-value $\leq 0.10$ are presented $\left({ }^{* *} P \leq 0.01 ;{ }^{*} 0.01<P \leq 0.05 ;+0.05<\right.$ $P \leq 0.10)$.

Overall, results indicate that it is possible to achieve similar pregnancy rates in intensive estrus detection programs. One important observation is that the adoption of AAM systems as part of large reproductive programs will likely vary from farm to farm. Work from Neves et al. (2012), Burnett et al. (2017), and DenisRobichaud et al. (2018b) demonstrated large variation by farm in the adoption of timed AI and AI upon AAM alerts within the same treatments. Collectively, these large field trials aimed to modify factors that are key to the performance of a reproduction program, particularly regarding the first AI. For instance, the voluntary waiting period varied from 50 to 100 DIM depending on the trial. Use of pre-synchronization protocols that focused on either induced estrus (prostaglandin-based) or cyclicity and ovulation synchrony (GnRH-based) was mostly tested. These studies demonstrated that the combination of methods (timed AI and AAM) can maintain high rates of conception while submitting a large number of animals to AI and minimizing use of pharmacological assistance to a certain extent.

It is undeniable that timed AI protocols are necessary as a safeguard for a proportion of animals that would not be bred upon estrus by a certain DIM threshold. The question of when to intervene with timed AI protocols is probably an area that could still gain valuable information from future research. The example of the work performed in Ontario (DenisRobichaud et al., 2018b) is perhaps the most extreme when comparing a timed AI-only program with one that allows long periods for spontaneous estrus detection after the end of the voluntary waiting period. In summary, several factors will influence the final result of the reproductive program at specific farms, but the literature suggests that AAM can be incorporated into reproductive programs without loss of efficiency, particularly compared with a timed AI intensive program. A recent study performed in British Columbia, Canada (Burnett et al., 2019a), aimed to test whether it was possible to use information from the AAM to modify a breeding decision at the farm level. Animals were divided into 4 groups based on the intensity of estrous expression and GnRH treatment at the time of AI. The hypothesis was that, based on previous results showing unfavorable ovulation failure rates and timing in cows expressing reduced intensity estrus, administration of GnRH to cows with low-intensity estrous expression would significantly improve pregnancy per AI. The group of cows that expressed a less intense estrus and received GnRH improved pregnancy per AI to a similar magnitude to that found in the groups with greater estrus intensity (Figure 7). However, this improvement in fertility was not explained by better ovulation rates, which indicates that another mechanism (e.g., ovulation timing, LH pulse frequency, amplitude, duration of the surge, or improved subsequent luteal function) is likely responsible for the improvement in fertility. It is also noteworthy that $\mathrm{GnRH}$ administration at AI also improved, although not to a significantly different degree, the pregnancy per AI rate in cows displaying intense estrous expression. Indeed, in cows with lesser estrous expression, those that received GnRH at insemination had a 9 percentage point greater pregnancy rate per AI than those that did not.

Finally, our group tested the effect of intensity of estrous expression on the success of ET and collection (Madureira et al., 2020). In the first experiment, Holstein heifers were superovulated for collection of embryos, whereas in the second experiment Holstein cows were synchronized and implanted with an embryo $7 \mathrm{~d}$ after estrus. Overall, heifers with greater intensity of activity at estrus yielded twice as many total and viable embryos. The recipient cows expressing estrus before ET had substantially greater pregnancy per ET than those that did not, and cows with greater intensity of estrous expression had 11 percentage point greater ET success (magnitude similar to that found in 


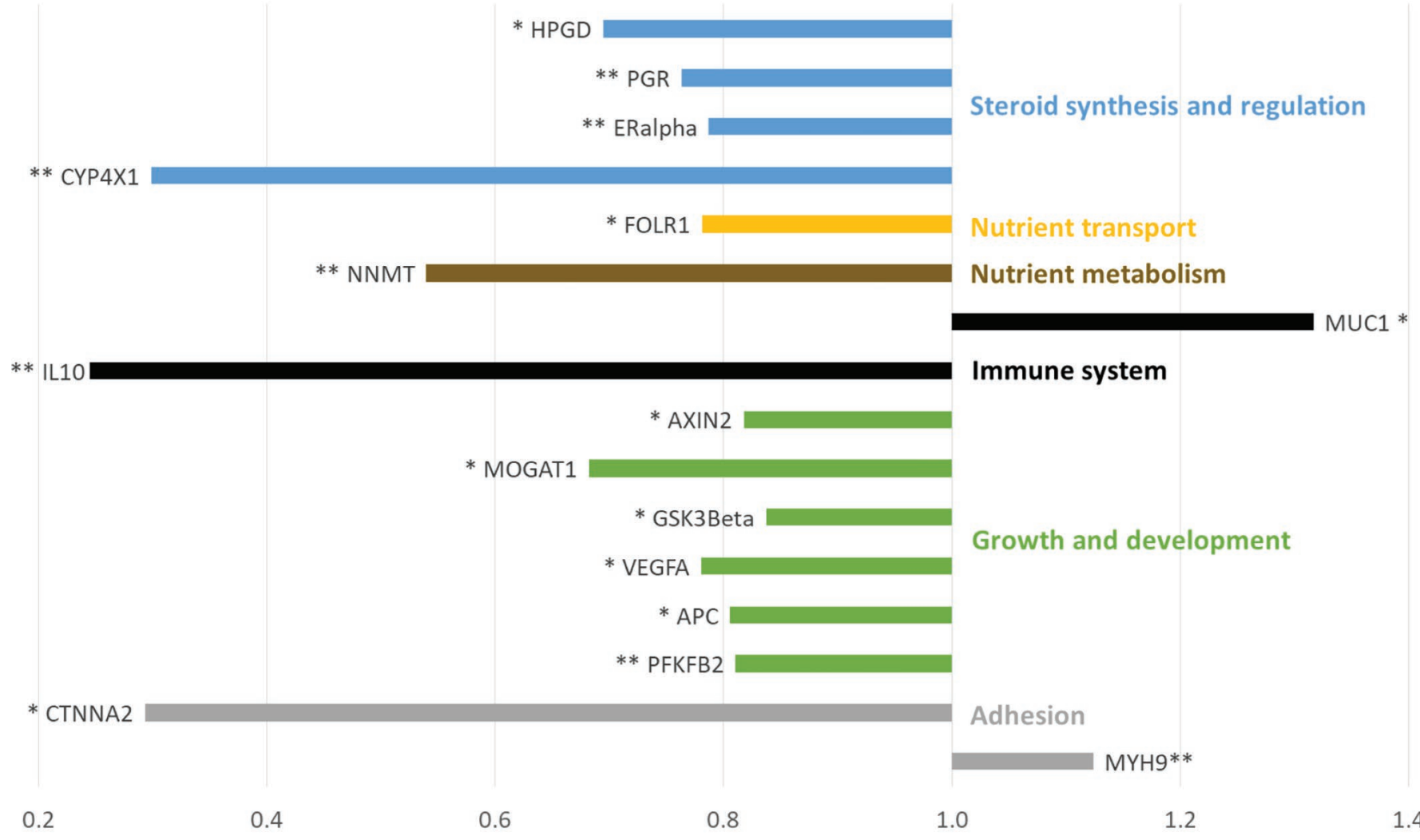

Figure 6. Odds ratios obtained from logistic regression models of the expression of each endometrium gene at d 15 of gestation in cows that expressed estrus signs (tailhead estrus detection patch) at insemination (referent: no estrus sign), adjusted for confounders (BCS, corpus luteum size, progesterone concentration, embryo length, follicle size, and IFN-tau concentration), in 100 nonlactating multiparous beef cows in Brazil. All inseminations were performed at fixed time, following an estrus synchronization protocol $[\mathrm{d}$-11: 2-mg estradiol benzoate injection and insertion of a progesterone releasing device (CIDR); $\mathrm{d}-4$ : 12.5-mg $\mathrm{PGF}_{2 \alpha}$ injection; $\mathrm{d}-2$ : removal of CIDR, and 0.6-mg estradiol cypionate and 300-IU equine chorionic gonadotropin injections; d 0: insemination]. Only genes for which the regression model had a $P$-value $\leq 0.05$ are presented $\left({ }^{* *} P \leq 0.01 ;{ }^{*} 0.01<P \leq 0.05\right.$; Souto et al., 2018).

studies using AI) than those with less-intense estrous expression.

\section{FUTURE DIRECTIONS}

Today, solid literature associates estrous behavior and fertility, with at least preliminary mechanistic explanations. Estrus and AAM data can and should be used to create a stream of studies with potential to increase knowledge of the basic biology of embryonic survival and to promote interdisciplinary collaboration between precision dairy technologies, data science, physiology, and genomics. In view of the large amount of behavioral data collected by automated sensors on dairy cows, and the potential of such data for application in dairy farms, a focus on the analysis of big data from AAM should prove informative, especially alongside careful collection of physiological data, as well as continuous research to address major literature gaps on the endocrine and molecular mechanisms that drive this association. Considering the now large-scale use of these AAM in commercial farms and the impressive capabilities of today's data science and computing capacity, a real possibility exists to considerably modify the identification of digital phenotypes captured by automated sensor technologies that predict fertility from different patterns of estrous expression.

\section{ACKNOWLEDGMENTS}

The authors thank all institutions, dairies, farm staff, and students involved with major projects from our research groups used in this review. Several studies received support by the Dairy Research Cluster Initiative II [Dairy Farmers of Canada (Ottawa, Canada), Agriculture and Agri-Food Canada (Ottawa, Canada), and Lactanet (Guelph, Canada), and the Canadian Dairy Commission (Ottawa, Canada)], the Natural Sciences 


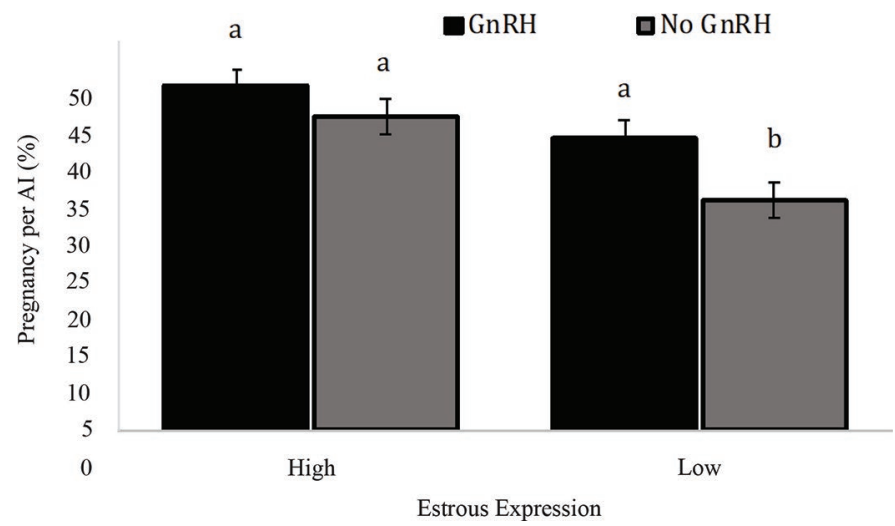

Figure 7. Interaction between $\mathrm{GnRH}$ treatment $(\mathrm{GnRH}$ or no $\mathrm{GnRH}$ ) and estrous expression (categorized using the median of each farm) on pregnancy per AI (LSM \pm SEM). The statistical model used ANOVA with estrus event nested within cow as a random effect using the GLIMMIX procedure of SAS (SAS Institute Inc., Cary, NC) adjusted for parity, BCS, and farm (random intercept) in 2,007 events of estrus from 852 lactating dairy cows from 3 farms in British Columbia (Burnett et al., 2019b). Lowercase letters (a, b) denote significant differences $(P<0.05)$.

and Engineering Research Council of Canada (Ottawa, Canada), Mitacs (Ottawa, Canada), the B.C. Dairy Association (Burnaby, Canada), the Westgen Endowment Fund, and other industry partners. The authors state that there were no conflict of interest and projects were designed and carried in accordance with the ethical standards required by the universities' policies.

\section{REFERENCES}

Aungier, S. P. M., J. F. Roche, P. Duffy, S. Scully, and M. A. Crowe. 2015. The relationship between activity clusters detected by an automatic activity monitor and endocrine changes during the periestrous period in lactating dairy cows. J. Dairy Sci. 98:1666-1684. https://doi.org/10.3168/jds.2013-7405.

Aungier, S. P. M., J. F. Roche, M. Sheehy, and M. A. Crowe. 2012. Effects of management and health on the use of activity monitoring for estrus detection in dairy cows. J. Dairy Sci. 95:2452-2466. https://doi.org/10.3168/jds.2011-4653.

Bisinotto, R. S., L. O. Castro, M. B. Pansani, C. D. Narciso, N. Martinez, L. D. P. Sinedino, T. L. C. Pinto, N. S. Van de Burgwal, H. M. Bosman, R. S. Surjus, W. W. Thatcher, and J. E. P. Santos. 2015. Progesterone supplementation to lactating dairy cows without a corpus luteum at initiation of the Ovsynch protocol. J. Dairy Sci. 98:2515-2528. https://doi.org/10.3168/jds.2014-9058.

Brehme, U., U. Stollberg, R. Holz, and T. Schleusener. 2008. ALT pedometer-New sensor-aided measurement system for improvement in oestrus detection. Comput. Electron. Agric. 62:73-80. https:// doi.org/10.1016/j.compag.2007.08.014.

Bridges, G. A., L. A. Helser, D. E. Grum, M. L. Mussard, C. L. Gasser, and M. L. Day. 2008. Decreasing the interval between GnRH and $\mathrm{PGF}_{2 \alpha}$ from 7 to 5 days and lengthening proestrus increases timed-AI pregnancy rates in beef cows. Theriogenology 69:843851. https://doi.org/10.1016/j.theriogenology.2007.12.011.

Burnett, T. A., A. M. L. Madureira, J. W. Bauer, and R. L. A. Cerri. 2019a. The interaction of estrous expression and GnRH administration at the time of AI on pregnancy and ovulation rates. WCDS Adv. Dairy Techno. 31:347.
Burnett, T. A., A. M. L. Madureira, J. W. Bauer, W. A. Gomes, and R. L. A. Cerri. 2019b. Interaction of estrous expression and progesterone on the impact of $\mathrm{GnRH}$ administration at the time of AI on pregnancy and ovulation rates. J. Dairy Sci. 102(Suppl. 1):275 (Abstr.)

Burnett, T. A., A. M. L. Madureira, B. F. Silper, A. C. C. Fernandes, and R. L. A. Cerri. 2017. Integrating an automated activity monitor into an artificial insemination program and the associated risk factors affecting reproductive performance of dairy cows. J. Dairy Sci. 100:5005-5018. https://doi.org/10.3168/jds.2016-12246.

Burnett, T. A., L. B. Polsky, M. Kaur, and R. L. A. Cerri. 2018. Effect of estrous expression on timing and failure of ovulation of Holstein dairy cows using automated activity monitors. J. Dairy Sci 101:11310-11320. https://doi.org/10.3168/jds.2018-15151.

Caraviello, D. Z., K. A. Weigel, P. M. Fricke, M. C. Wiltbank, M. J. Florent, N. B. Cook, K. V. Nordlund, N. R. Zwald, and C. L. Rawson. 2006. Survey of management practices on reproductive performance of dairy cattle on large US commercial farms. J. Dairy Sci. 89:4723-4735. https://doi.org/10.3168/jds.S0022 -0302(06)72522-X.

Cerri, R. L. A., R. C. Chebel, F. Rivera, C. D. Narciso, R. A. Oliveira, M. Amstalden, G. M. Baez-Sandoval, L. J. Oliveira, W. W. Thatcher, and J. E. P. Santos. 2011. Concentration of progesterone during the development of the ovulatory follicle: II. Ovarian and uterine responses. J. Dairy Sci. 94:3352-3365. https://doi.org/10 $.3168 /$ jds.2010-3735.

Cerri, R. L. A., H. M. Rutigliano, R. C. Chebel, and J. E. P. Santos. 2009. Period of dominance of the ovulatory follicle influences embryo quality in lactating dairy cows. Reproduction 137:813-823. https://doi.org/10.1530/REP-08-0242.

Cerri, R. L. A., J. E. P. Santos, S. O. Juchem, K. N. Galvão, and R. C. Chebel. 2004. Timed artificial insemination with estradiol cypionate or insemination at estrus in high-producing dairy cows. J. Dairy Sci. 87:3704-3715. https://doi.org/10.3168/jds.S0022 -0302(04)73509-2.

Cooke, R. F., K. G. Pohler, J. L. M. Vasconcelos, and R. L. A. Cerri. 2019. Estrous expression during a fixed-time artificial insemination protocol enhances development and interferon-tau messenger RNA expression in conceptuses from Bos indicus beef cows. Animal 13:2569-2575. https://doi.org/10.1017/S1751731119000636.

Davoodi, S., R. F. Cooke, A. C. Fernandes, B. I. Cappellozza, J. L. Vasconcelos, and R. L. Cerri. 2016. Expression of estrus modifies the gene expression profile in reproductive tissues on Day 19 of gestation in beef cows. Theriogenology 85:645-655. https://doi .org/10.1016/j.theriogenology.2015.10.002.

De Mol, R. M., E. J. B. Bleumer, P. H. Hogewerf, and A. H. Ipema. 2009. Recording of dairy cow behaviour with wireless accelerometers. Pages 349-356 in Precision Livestock Farming '09. C. Lokhorst and P. W. G. Groot Koerkamp, ed. Wageningen Academic Publishers, Wageningen, the Netherlands.

Denis-Robichaud, J., R. L. A. Cerri, A. Jones-Bitton, and S. J. LeBlanc. 2016. Survey of reproduction management on Canadian dairy farms. J. Dairy Sci. 99:9339-9351. https://doi.org/10.3168/jds .2016-11445.

Denis-Robichaud, J., R. L. A. Cerri, A. Jones-Bitton, and S. J. LeBlanc. 2018a. Dairy producers' attitudes toward reproductive management and performance on Canadian dairy farms. J. Dairy Sci. 101:850-860. https://doi.org/10.3168/jds.2016-12416.

Denis-Robichaud, J., R. L. A. Cerri, A. Jones-Bitton, and S. J. LeBlanc. 2018b. Performance of automated activity monitoring systems used in combination with timed artificial insemination compared to timed artificial insemination only in early lactation in dairy cows. J. Dairy Sci. 101:624-636. https://doi.org/10.3168/ jds.2016-12256.

Denis-Robichaud, J., S. J. LeBlanc, A. Jones-Bitton, B. F. Silper, and R. L. A. Cerri. 2018c. Pilot study to evaluate the association between the length of the luteal phase and estrous activity detected by automated activity monitoring in dairy cows. Front. Vet. Sci. $5: 210$. 
Firk, R., E. Stamer, W. Junge, and J. Krieter. 2002. Automation of oestrus detection in dairy cows: A review. Livest. Prod. Sci. 75:219-232. https://doi.org/10.1016/S0301-6226(01)00323-2.

Fricke, P. M., J. O. Giordano, A. Valenza, G. Lopes Jr., M. C. Amundson, and P. D. Carvalho. 2014. Reproductive performance of lactating dairy cows managed for first service using timed artificial insemination with or without detection of estrus using an activitymonitoring system. J. Dairy Sci. 97:2771-2781. https://doi.org/10 $.3168 /$ jds.2013-7366.

Galvão, K. N., J. E. Santos, S. O. Juchem, R. L. A. Cerri, A. C. Coscioni, and M. Villaseñor. 2004. Effect of addition of a progesterone intravaginal insert to a timed insemination protocol using estradiol cypionate on ovulation rate, pregnancy rate, and late embryonic loss in lactating dairy cows. J. Anim. Sci. 82:3508-3517. https://doi.org/10.2527/2004.82123508x.

Hockey, C., J. Morton, S. Norman, and M. McGowan. 2010. Evaluation of a neck mounted 2-hourly activity meter system for detecting cows about to ovulate in two paddock-based Australian dairy herds. Reprod. Domest. Anim. 45:e107-e117.

Holman, A., J. Thompson, J. E. Routly, J. Cameron, D. N. Jones, D. Grove-White, R. F. Smith, and H. Dobson. 2011. Comparison of oestrus detection methods in dairy cattle. Vet. Rec. 169:47-53. https://doi.org/10.1136/vr.d2344.

Jónsson, R., M. Blanke, N. K. Poulsen, F. Caponetti, and S. Højsgaard. 2011. Oestrus detection in dairy cows from activity and lying data using on-line individual models. Comput. Electron. Agric. 76:6-15. https://doi.org/10.1016/j.compag.2010.12.014.

LeRoy, C. N. S., J. S. Walton, and S. J. LeBlanc. 2018. Estrous detection intensity and accuracy and optimal timing of insemination with automated activity monitors for dairy cows. J. Dairy Sci. 101:1638-1647. https://doi.org/10.3168/jds.2017-13505.

Lopez, H., L. D. Satter, and M. C. Wiltbank. 2004. Relationship between level of milk production and estrous behavior of lactating dairy cows. Anim. Reprod. Sci. 81:209-223. https://doi.org/10 .1016/j.anireprosci.2003.10.009.

López-Gatius, F., P. Santolaria, I. Mundet, and J. L. Yániz. 2005. Walking activity at estrus and subsequent fertility in dairy cows. Theriogenology 63:1419-1429. https://doi.org/10.1016/j theriogenology.2004.07.007.

Løvendahl, P., and M. G. G. Chagunda. 2010. On the use of physical activity monitoring for estrus detection in dairy cows. J. Dairy Sci. 93:249-259. https://doi.org/10.3168/jds.2008-1721.

Madureira, A. M. L., T. A. Burnett, J. W. Bauer, W. A. Gomes, and R. L. A. Cerri. 2019a. Length of follicular and luteal phase is associated with estrous expression. J. Dairy Sci. 102(Suppl. 1):359. (Abstr.)

Madureira, A. M. L., T. A. Burnett, K. G. Pohler, T. G. Guida, C. P. Sanchez Jr., J. L. M. Vasconcelos, and R. L. A. Cerri. 2020. Short communication: Greater intensity of estrous expression is associated with improved embryo viability from superovulated Holstein heifers. J. Dairy Sci. 103: 5641-5646. https://doi.org/10.3168/jds 2019-17772.

Madureira, A. M. L., T. A. Burnett, J. L. M. Vasconcelos, and R. L. A. Cerri. 2018. Impact of estrous expression on progesterone concentrations and its association with fertility. J. Dairy Sci. 101(Suppl. 2):83. (Abstr.)

Madureira, A. M. L., L. B. Polsky, T. A. Burnett, B. F. Silper, S. Soriano, A. F. Sica, K. G. Pohler, J. L. M. Vasconcelos, and R. L. A. Cerri. 2019b. Intensity of estrus following an estradiol-progesterone-based ovulation synchronization protocol influences fertility outcomes. J. Dairy Sci. 102:3598-3608. https://doi.org/10.3168/ jds.2018-15129.

Madureira, A. M. L., B. F. Silper, T. A. Burnett, L. B. Polsky, L. H. Cruppe, J. L. M. Vasconcelos, and R. L. A. Cerri. 2015. Factors affecting expression of estrus measured by activity monitors and conception risk of lactating dairy cows. J. Dairy Sci. 98:7003-7014. https://doi.org/10.3168/jds.2015-9672.

Morris, M. J., S. L. Walker, D. N. Jones, J. E. Routly, R. F. Smith, and H. Dobson. 2009. Influence of somatic cell count, body condition and lameness on follicular growth and ovulation in dairy cows. Theriogenology 71:801-806. https://doi.org/10.1016/j .theriogenology.2008.10.001.

Neves, R. C., K. E. Leslie, J. S. Walton, and S. J. Leblanc. 2012. Reproductive performance with an automated activity monitoring system versus a synchronized breeding program. J. Dairy Sci. 95:5683-5693. https://doi.org/10.3168/jds.2011-5264.

Peralta, O. A., R. E. Pearson, and R. L. Nebel. 2005. Comparison of three estrus detection systems during summer in a large commercial dairy herd. Anim. Reprod. Sci. 87:59-72. https://doi.org/10 $.1016 /$ j.anireprosci.2004.10.003.

Pereira, M. H. C., A. D. Rodrigues, R. J. De Carvalho, M. C. Wiltbank, and J. L. M. Vasconcelos. 2014. Increasing length of an estradiol and progesterone timed artificial insemination protocol decreases pregnancy losses in lactating dairy cows. J. Dairy Sci. 97:1454-1464. https://doi.org/10.3168/jds.2013-7287.

Pereira, M. H. C., M. C. Wiltbank, and J. L. M. Vasconcelos. 2016. Expression of estrus improves fertility and decreases pregnancy losses in lactating dairy cows that receive artificial insemination or embryo transfer. J. Dairy Sci. 99:2237-2247. https://doi.org/10 3168/jds.2015-9903.

Ribeiro, E. S., G. Gomes, L. F. Greco, R. L. A. Cerri, A. Vieira-Neto, P. L. J. Monteiro Jr., F. S. Lima, R. S. Bisinotto, W. W. Thatcher, and J. E. P. Santos. 2016. Carryover effect of postpartum inflammatory diseases on developmental biology and fertility in lactating dairy cows. J. Dairy Sci. 99:2201-2220. https://doi.org/10.3168/ jds.2015-10337.

Rivera, F., C. Narciso, R. Oliveira, R. L. A. Cerri, A. Correa-Calderón, R. C. Chebel, and J. E. P. Santos. 2010. Effect of bovine somatotropin $(500 \mathrm{mg})$ administered at ten-day intervals on ovulatory responses, expression of estrus, and fertility in dairy cows. J. Dairy Sci. 93:1500-1510. https://doi.org/10.3168/jds.2009-2489.

Rodrigues, A. D., R. F. Cooke, R. S. Cipriano, L. G. T. Silva, R. L. A. Cerri, L. H. Cruppe, M. Meneghetti, K. G. Pohler, and J. L. M. Vasconcelos. 2018. Impacts of estrus expression and intensity during a timed-AI protocol on variables associated with fertility and pregnancy success in Bos indicus-influenced beef cows. J. Anim. Sci. 96:236-249. https://doi.org/10.1093/jas/skx043.

Roelofs, J. B., F. J. van Eerdenburg, N. M. Soede, and B. Kemp. 2005. Pedometer readings for estrous detection and as predictor for time of ovulation in dairy cattle. Theriogenology 64:1690-1703. https:/ /doi.org/10.1016/j.theriogenology.2005.04.004.

Rutten, C. J., A. G. J. Velthuis, W. Steeneveld, and H. Hogeveen. 2013. Invited review: Sensors to support health management on dairy farms. J. Dairy Sci. 96:1928-1952. https://doi.org/10.3168/ jds.2012-6107.

Sakaguchi, M., R. Fujiki, K. Yabuuchi, Y. Takahashi, and M. Aoki. 2007. Reliability of estrous detection in Holstein heifers using a radiotelemetric pedometer located on the neck or legs under different rearing conditions. J. Reprod. Dev. 53:819-828. https://doi .org/10.1262/jrd.18099.

Santos, J. E. P., H. M. Rutigliano, and M. F. Sá Filho. 2009. Risk factors for resumption of postpartum estrous cycles and embryonic survival in lactating dairy cows. Anim. Reprod. Sci. 110:207-221. https://doi.org/10.1016/j.anireprosci.2008.01.014.

Sartori, R., J. M. Haughian, R. D. Shaver, G. J. M. Rosa, and M. C. Wiltbank. 2004. Comparison of ovarian function and circulating steroids in estrous cycles of Holstein heifers and lactating cows. J. Dairy Sci. 87:905-920. https://doi.org/10.3168/jds.S0022 -0302(04)73235-X.

Sartori, R., G. J. M. Rosa, and M. C. Wiltbank. 2002. Ovarian structures and circulating steroids in heifers and lactating cows in summer and lactating and dry cows in winter. J. Dairy Sci. 85:28132822. https://doi.org/10.3168/jds.S0022-0302(02)74368-3.

Silper, B. F., A. M. L. Madureira, M. Kaur, T. A. Burnett, and R. L. A. Cerri. 2015a. Short communication: Comparison of estrus characteristics in Holstein heifers by 2 activity monitoring systems. J. Dairy Sci. 98:3158-3165. https://doi.org/10.3168/jds.2014-9185.

Silper, B. F., A. M. L. Madureira, L. B. Polsky, S. Soriano, A. F. Sica, J. L. M. Vasconcelos, and R. L. A. Cerri. 2017. Daily lying behavior of lactating Holstein cows during an estrus synchroni- 
zation protocol and its associations with fertility. J. Dairy Sci. 100:8484-8495. https://doi.org/10.3168/jds.2016-12160.

Silper, B. F., L. Polsky, J. Luu, T. A. Burnett, J. Rushen, A. M. de Passillé, J. Rushen, and R. L. A. Cerri. 2015b. Automated and visual measurements of estrous behavior and their sources of variation in Holstein heifers II: Standing and lying patterns. Theriogenology 84:333-341. https://doi.org/10.1016/j.theriogenology 2014.12.030

Silper, B. F., I. Robles, A. M. L. Madureira, T. A. Burnett, M. M. Reis, A. M. de Passillé, J. Rushen, and R. L. A. Cerri. 2015c. Automated and visual measurements of estrous behavior and their sources of variation in Holstein heifers I: Walking activity and behavior frequency. Theriogenology 84:312-320. https://doi.org/ 10.1016/j.theriogenology.2014.12.029

Souto, P. F. M. P., R. F. Cooke, R. Cipriano, B. F. Silper, and R. L. A. Cerri. 2018. Differential gene expression of day 15 endometrium of pregnant Bos indicus beef cows according to expression of estrus at timed-AI. J. Anim. Sci. 96(Suppl. 3):354-355. https://doi.org/ 10.1093/jas/sky404.780.

Stevenson, J. S. 2001. A review of oestrous behaviour and detection in dairy cows. BSAP Occas. Pub. 26:43-62.

Stevenson, J. S., S. L. Hill, R. L. Nebel, and J. M. Dejarnette. 2014. Ovulation timing and conception risk after automated activity monitoring in lactating dairy cows. J. Dairy Sci. 97:4296-4308. https://doi.org/10.3168/jds.2013-7873.

Valenza, A., J. O. Giordano, G. Lopes Jr., L. Vincenti, M. C. Amundson, and P. M. Fricke. 2012. Assessment of an accelerometer system for detection of estrus and treatment with gonadotropin-releasing hormone at the time of insemination in lactating dairy cows. J. Dairy Sci. 95:7115-7127. https://doi.org/10.3168/jds.2012-5639.

Vasconcelos, J. L. M., S. Sangsritavong, S. J. Tsai, and M. C. Wiltbank. 2003. Acute reduction in serum progesterone concentrations after feed intake in dairy cows. Theriogenology 60:795-807. https: //doi.org/10.1016/S0093-691X(03)00102-X.

Veerkamp, R. F., J. K. Oldenbroek, H. J. van der Gaast, and J. H. J. van der Werf. 2000. Genetic correlation between days until start of luteal activity and milk yield, energy balance, and live weights. J. Dairy Sci. 83:577-583. https://doi.org/10.3168/jds.S0022 $-0302(00) 74917-4$

Walker, S. L., R. F. Smith, J. E. Routly, D. N. Jones, M. J. Morris, and H. Dobson. 2008. Lameness, activity time-budgets, and estrus expression in dairy cattle. J. Dairy Sci. 91:4552-4559. https://doi .org $/ 10.3168 /$ jds.2008-1048.

Walker, W. L., R. L. Nebel, and M. L. McGilliard. 1996. Time of ovulation relative to mounting activity in dairy cattle. J. Dairy Sci. 79:1555-1561. https://doi.org/10.3168/jds.S0022-0302(96)76517 $-7$.

Williams, J., T. Ntallaris, J. E. Routly, D. N. Jones, J. Cameron, A Holman-Coates, R. F. Smith, P. Humblot, and H. Dobson. 2018 Association of production diseases with motor activity-sensing devices and milk progesterone concentrations in dairy cows. Theriogenology 118:57-62. https://doi.org/10.1016/j.theriogenology.2018 .05.038. 